\title{
Coexistence of Small Bowel Adenocarcinoma and Chronic Inflammatory Bowel Disease (IBD): Case Report and Review of the Literature
}

Amine Hamdane ${ }^{1 *}$, Omar Marghich ${ }^{1}$, Jamal Zhar ${ }^{1}$, Ouaddi Mouaqit ${ }^{1}$, El Bachir Benjelloun ${ }^{1}$, Ousadden Abdelmalek ${ }^{1}$, Khalid AitTaleb ${ }^{1}$, Hicham El Bouhaddouti ${ }^{1}$

${ }^{1}$ Faculty of Medicine and Pharmacy, Sidi Mohammed Ben Abdellah university of Fez, Morocco, Visceral Surgery department A, CHU Hassan II, Fez, Morocco

DOI: $\underline{10.36347 / \text { sasjs.2021.v07i05.004 }}$

| Received: 22.03.2021 | Accepted: 01.05.2021 | Published: 07.05.2021

*Corresponding author: Amine Hamdane

Abstract

Small bowel tumors are rare, rating between $1 \%$ and $6 \%$ of all gastrointestinal tumors [1]. The association of small bowel tumor is reported in Crohn's disease (CD) [2]. We report a case of a 40-year-old female patient with a history of Hemorrhagic Recto-colitis admitted for an occlusive small bowel tumor, treated by a carcinologic resection.

Keywords: Small bowel tumors, gastrointestinal tumors, Crohn's disease (CD), Inflammatory Bowel Disease (IBD). Copyright $\odot 2021$ The Author(s): This is an open-access article distributed under the terms of the Creative Commons Attribution 4.0 International License (CC BY-NC 4.0) which permits unrestricted use, distribution, and reproduction in any medium for non-commercial use provided the original author and source are credited.

\section{INTRODUCTION}

Small bowel adenocarcinomas are 50 times less common than colonic adenocarcinomas [1-3], despite the fact that the small intestine accounts for $75 \%$ of the length of the gastrointestinal tract and $90 \%$ of its mucosal surface [4-6]. The symptomatology of small bowel tumors is not very specific. Despite advances in endoscopic and radiological examination, the exploration of these tumors remains difficult. Surgery is the effective treatment [5]. The association of bowel cancer and Crohn's disease (CD) is well known [2]. The prognosis is often poor due to delayed diagnosis [5].

\section{PATIENT AND OBSERVATION}

A 40-years-old female patientoperated for severe acute colitis on probable Hemorrhagic Rectocolitis for which she underwent a total colectomy with ileo-rectal anastomosis 5 years ago have been admitted for an occlusive syndrome.

In her medical history we find also adrenal insufficiency under hydrocortisone, cortico-induced diabetes, psoriasis, deep vein thrombosis under antiplatelet drugs, pulmonary tuberculosis declared cured.
Clinical examination on admission found a tachycardy with a distended and tympanic abdomen. Rectal examination showed an empty rectal ampulla. Abdominal X-ray showed the presence of hydro-aeric levels. Abdominal CT scan revealed moderate intestinal distension upstream of a tumour-like thickening of the small bowel wish was responsible for an upstream occlusion (Figures-1).

The patient was admitted to the operating room, where surgical exploration revealed a tumor-like stenosis located at $1.5 \mathrm{~m}$ from the Treitz angle and 1.9 $\mathrm{m}$ from the ileo-rectal anastomosis (Figure-2), which was without any particularities. A bowel resection was performed, removing the stenosis and respecting the safety margins, with the creation of a bowel-gravel anastomosis. The postoperative course was uneventful. The anatomopathological examination of the surgical sample was in favor of a moderately differentiated and infiltrating adenocarcinoma reaching the subserosa with microscopically clean surgical resection limits. The diagnosis of the adenocarcinoma in this patient was a rare occurrence in our setting, so the initial suspicion of Hemorrhagic Recto-colitis was questioned, hence the suspicion of Crohn's disease. The patient was subsequently put under clinical, endoscopic and radiological surveillance with a favorable evolution. 


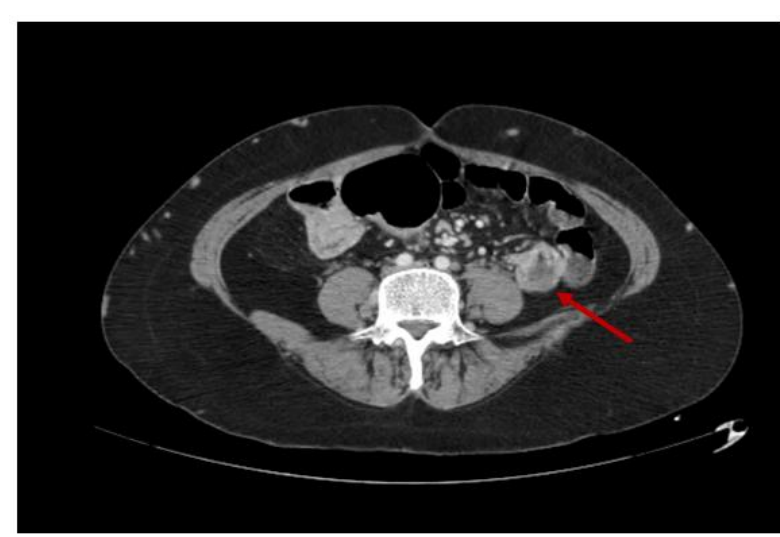

Fig-1: moderate intestinal distension upstream of a tumour-like thickening of the small bowel

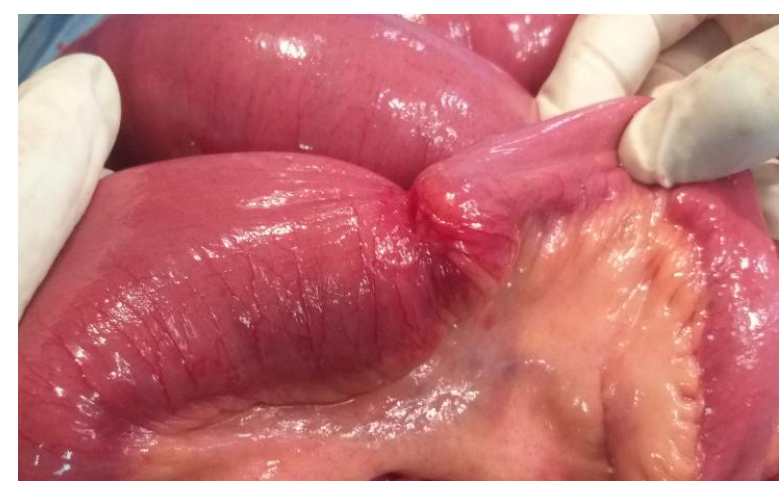

Fig-2: Tumor-like stenosis

\section{DISCUSSION}

Small bowel tumors are rare, their incidence is low due to the rapid regeneration of the small bowel mucosa, the low bacterial density and the low production of carcinogenic metabolites, as well as the high concentration of $\operatorname{IgA}$ in the ileum which prevents tumor growth [4]. However, the association of adenocarcinoma with chronic intestinal disease (CID), particularly Crohn's disease, is recognized as a risk factor for colon cancer despite the low incidence estimated at $2 \%$ for disease duration of 25 years [4]. In Hemorrhagic Recto-colitis, the risk of colorectal cancer is estimated to be approximately $7-14 \%$ for 25 years of disease duration [7-9], with current data suggesting that the rate of colorectal cancer increases to $30 \%$ for duration of disease exceeding 35 years $[7,10,11]$. The diagnostic difficulty of small bowel adenocarcinoma in association with IBD is related to the absence of specific clinical manifestations and the difficulty of endoscopic exploration of the small bowel despite the reliability of certain examinations in the exploration of the small bowel, notably enteroscan, entero-MRI, and double balloon enteroscopy [4]. Surgical removal of these tumours in IBD, particularly by laparoscopy, remains the mainstay of treatment for small bowel cancer. The prognosis of small bowel adenocarcinomas remains poor as the majority of these are diagnosed at an advanced stage of the disease [1, 4-6]. The main factor of good prognosis is surgical excision with healthy surgical margins with absence of lymph node involvement $[4,12,13]$.

\section{CONCLUSION}

IBD patients are recognized as a population at risk of developing digestive cancers. In the case of non response to treatment, especially in Crohn's disease, small bowel tumours should be suspected in order to allow early management of these tumors and to improve the prognosis of the patients.

\section{REFERENCES}

1. Mrabet FZ, Brahmi SA, Benbrahim Z, Akasbi Y, Mekkaoui AE, Oussaden A, Znati K, Amarti A, Ibrahimi A, Maazaz K, Taleb KA. Les adénocarcinomes du grêle. A propos de deux cas Adenocarcinoma of the small bowel. About two cases. 2009; 1(1):26-28.

2. Samlani-Sebbane Z, Gharaba S, Narjis Y, Rabbani K, Diffaa A, Krati K, Finech B. The coexistence of carcinoid tumours and ileal Crohn's disease: a new case!. Acta Endoscopica. 2012 Sep 1;42(4):194-6.

3. Jemal A, Siegel R, Ward E, Hao Y, Xu J, Murray T, Thun MJ. Cancer statistics, 2008. CA: a cancer journal for clinicians. 2008 Mar;58(2):71-96.

4. Barrière J, Follana F, Chevallier P, Carlot-Leccia N, Caroli-Bosc FX, Hébuterne X. Small bowel cancer diagnosed during the fi rst $\mathrm{fl}$ are-up of a Crohn's disease.

5. Bonnet J, Lemann M. Tumeurs de l'intestin grêle. Encycl Méd Chir; Gastroentérologie, 1997; 9-067-C-10.

6. Zaanan A, Afchain $\mathrm{P}$, Carrere $\mathrm{N}$, Aparicio $\mathrm{T}$. Adénocarcinome de l'intestin grêle. Gastroenterol Clin Biol. 2010; 34(6-7):371-379.

7. Bernstein $\mathrm{CN}$, Blanchard JF, Kliewer E, Wajda A. Cancer risk in patients with inflammatory bowel disease: a population based study. Cancer. 2001 Feb 15;91(4):854-62.

8. Gyde SN, Prior P, Allan RN, Stevens A, Jewell DP, Truelove SC, Lofberg R, Brostrom O, Hellers G. Colorectal cancer in ulcerative colitis: a cohort study of primary referrals from three centres. Gut. 1988 Feb 1;29(2):206-17.

9. Lofburg R, Brostrom O, Karen P, Tribukait B, Ost A. Colonoscopic surveillance in long-standing total ulcerative colitis a 15 years follow-up study. Gastroenterology. 1999;99:1021-31.

10. Linfberg B, Persson B, Veress B, Ingelman-Sandberg H, Grangvist S. Twenty years colonoscopic surveillance of patients with ulcerative colitis. Detection of dysplastic and malignant transformation. Scand J gastroenterol, 1996;31:1195-204.

11. Ekbom A, Helmick C, Zack M, Adami HO. Ulcerative colitis and colorectal cancer: a population-based study. New England journal of medicine. 1990 Nov 1;323(18):1228-33.

12. Bauer RL, Palmer ML, Bauer AM, Nava HR, Douglass HO. Adenocarcinoma of the small intestine: 21-year review of diagnosis, treatment, and prognosis. Annals of surgical oncology. 1994 May;1(3):183-8.

13. Dabaja BS, Suki D, Pro B, Bonnen M, Ajani J. Adenocarcinoma of the small bowel: presentation, prognostic factors, and outcome of 217 patients. Cancer: Interdisciplinary International Journal of the American Cancer Society. 2004 Aug 1;101(3):518-26. 